\title{
Are single odorous components of a predator sufficient to elicit defensive behaviors in prey species?
}

OPEN ACCESS

Edited by:

Thomas Endres,

Otto-von-Guericke University,

Germany

Reviewed by:

Micheal Baum,

Boston University, USA

Lorey K. Takahashi,

University of Hawaii at Manoa, USA

${ }^{*}$ Correspondence:

Raimund Apfelbach,

Animal Physiology, Institute for Neurobiology, University of Tübingen,

Auf der Morgenstelle 28,

72076 Tübingen, Germany raimund.apfelbach@uni-tuebingen.de

Specialty section:

This article was submitted to Systems Biology,

a section of the journal Frontiers in Neuroscience

Received: 30 May 2015 Accepted: 13 July 2015

Published: 29 July 2015

Citation: Apfelbach R, Parsons MH, Soini HA and Novotny MV (2015) Are single odorous components of a predator sufficient to elicit defensive behaviors in prey species?

Front. Neurosci. 9:263.

doi: 10.3389/fnins.2015.00263

\author{
Raimund Apfelbach ${ }^{*}$, Michael H. Parsons ${ }^{2}$, Helena A. Soini ${ }^{3}$ and Milos V. Novotny ${ }^{3}$ \\ ${ }^{1}$ Animal Physiology, Institute for Neurobiology, University of Tübingen, Tübingen, Germany, ${ }^{2}$ Department of Biology, Hofstra \\ University, Hempstead, NY, USA, ${ }^{3}$ Department of Chemistry, Institute for Pheromone Research, Indiana University, \\ Bloomington, IN, USA
}

When exposed to the odor of a sympatric predator, prey animals typically display escape or defensive responses. These phenomena have been well-documented, especially in rodents, when exposed to the odor of a cat, ferret, or fox. As a result of these experiments new discussions center on the following questions: (1) is a single volatile compound such as a major or a minor mixture constituent in urine or feces, emitted by the predator sufficient to cause defensive reactions in a potential prey species or (2) is a whole array of odors required to elicit a response and (3) will the relative size or escapability of the prey as compared to the predator influence responsiveness. Most predator-prey studies on this topic have been performed in the laboratory or under semi-natural conditions. Field studies could help to find answers to these questions. Australian mammals are completely naive toward the introduced placental carnivores. That offers ideal opportunities to analyze in the field the responses of potential prey species to unknown predator odors. During the last decades researchers have accumulated an enormous amount of data exploring the effects of eutherian predator odors on native marsupial mammals. In this review, we will give a survey about the development of olfactory research, chemical signals and their influence on the behavior and-in some cases - physiology of prey species. In addition, we report on the effects of predator odor experiments performed under natural conditions in Australia. When studying all these literature we learned that data gained under controlled laboratory conditions elucidate the role of individual odors on brain structures and ultimately on a comparatively narrow range behaviors. In contrast to single odors odor arrays mimic much more the situation prey animals are confronted to in nature. Therefore, a broad range of methodology - from chemistry to ecology including anatomy, physiology, and behavior - is needed to understand all the different (relevant) stimuli that govern and guide the interactions between a predator and its potential prey.

Keywords: predator odors, aging of odors, predator naive prey, odor avoidance, field studies in Australia 


\section{Development of Olfactory Research}

Chemical ecology is one of the most fascinating themes in modern biology. Chemical compounds are essential in intraspecific communication as well as in information exchange between different species. Chemical signals are involved in the defense of prey species against predators, competitors, parasites, microbes, and other potentially harmful organisms (Derby and Aggio, 2011). In short, the challenge in chemical ecology is to demonstrate how chemically mediated interactions steer ecology and evolutionary processes at all levels of ecological organization (Vet, 1999).

Among the first scientific reports on chemicals secreted by a carnivore was the paper by Albone and Perry (1975). The authors analyzed the anal sac secretion of the red fox (Vulpes vulpes) and of the lion (Panthera leo). The major components of red fox urine deposited in their tracks on snow during the mating and breeding season were later structurally identified (Jorgenson et al., 1978). It was noted that the characteristic "skunk-like odor" of these fox tracks is likely due to sulfur-containing constituents of urine. The synthetic blends of the major urinary constituents were made and deposited in the fox natural habitat to test their ecological significance (Whitten et al., 1980; Wilson et al., 1980). Seasonal variations in the excretion of captive fox urinary volatiles were further investigated (Bailey et al., 1980). During the 1970s and early 1980s, chemical constituents of the defensive secretions of the striped skunk (Mephitis mephitis) were also positively identified as mainly sulfur-containing compounds (Andersen and Bernstein, 1975; Andersen et al., 1982).

During roughly the same time period, the chemist Schildknecht and his coworkers analyzed the anal gland secretions of several mustelid species including the mink (Mustela vison), the polecat (Mustela putorius) and the badger (Meles meles) (Schildknecht et al., 1976, 1981; Schildknecht and Birkner, 1983; Schildknecht and Hiller, 1984). Considering the limited analytical capabilities at that time, these studies are still among the most detailed reports on semiochemicals in carnivores. The authors reported 3,3-dimethyl-1,2-dithiolane, 2,2-dimethyl-, cis- and trans-2,3-dimethyl-, 2-propyl-, and 2pentylthietane characteristic to the polecat (Mustela putorius L.) and the ferret (Mustela putorius furo). In the odorous secretion of the stoat (Mustela ermine) they found 2-methyl-, 2-opyl-, and 2pentylthietan. Similar sulfur-containing components were found in the secretion of the anal glands of weasel (Mustela nivalis). On the contrary, no sulfur-containing compounds were observed in the beech-marten (Martes foina) and the pine-marten (Martes martes) odoriferous secretions (Schildknecht and Birkner, 1983).

As mustelids became more popular in scientific research, more research groups focused on the anal secretions of mustelid species (Crump, 1980; Brinck et al., 1983; Crump and Moors, 1985). The general ideas about the importance of chemical communication in mammals were significantly advanced by the first reports of chemical structures of primer pheromones in rodents (Jemiolo et al., 1986; Novotny et al., 1986, 1990) starting in the 1980s. Importantly, the analytical methodologies developed for this research became a major stimulus for broad studies of ecological significance. All these studies have opened avenues for biologists to investigate chemical communication within individual species and the relationship between predators and prey.

The chemical compounds emitted by a species and the effects they might cause in another species became hot spots of scientific interest. Among the first to launch this research line were Nolte et al. (1994). They sparked a field of highest scientific interest when they published their paper "why are predator odors aversive to prey?" This question is still investigated and debated by biologists, chemists, and ecologists. Until now, no one has introduced an adaptive framework to organize the data and speculations for the broad range of varying results. We will propose a novel adaptive framework to compare the overall risk that a prey animal might accept against the degree of danger represented by one or more predator cues. The most obvious indicator of risk relates to how likely a single encounter of predator-prey would result in foregone feeding or mating opportunities, serious injury, or demise e.g., the ability of the prey to defend, suppress, or survive the encounter. For this reason we propose a likelihood of risk category by the relative size or elusiveness of the prey as compared to the predator (supplement, Table 1).

Implicit in our model is an understanding that smaller, more vulnerable, prey may respond aversively to single-molecule odors while larger, or most elusive, prey may attenuate their response according to composite molecules that convey additional information about the degree of risk inherent in the scent. For instance small kangaroos and wallabies may respond aversively to domestic dog urine, predators they have had no evolutionary contact with - or possibly even aged, chemically degraded scents. However, larger macropods such as red kangaroos, may not respond to a single compound. They likely require complex scents that include additional information on the size and recentness of void from the predator, before foregoing mating opportunities or leaving a food patch. It would after all, be evolutionarily disadvantageous for a $50+\mathrm{kg}$ herbivore to respond to wastes secreted by a $700 \mathrm{~g}$, predator.

Much of the present research concentrates on three basic topics: (1) How effective are carnivorous chemical compounds as repellents to prey species of different size, (2) do such chemical compounds suppress breeding success in prey species and (3) which brain structures of the prey species are involved in the avoidance/fear responses. A comprehensive review of field and laboratory studies about the positive and negative effects of predator odors on mammalian prey species has been reported in detail (Apfelbach et al., 2005). The involvement of brain structures in the avoidance/fear responses has been recently very well-addressed by Takahashi (2014).

The effects of predator odors or individual compounds in a complex odor source can be evaluated in the laboratory and in the field. Besides natural predator odors, synthetic predator semiochemicals (Lindgren et al., 1995) and-in another studya range of seven predator odors and, in addition diesel oil, as repellents for wildlife have been used in field studies (Engelhart and Müller-Schwarze, 1995). In that study, coyote (Canis latrans), lynx (Lynx canadensis) and river otter (Lutra canadensis) odors had the strongest effects, while diesel oil was effective too, but the effects were weaker. So far, no field data are available about the 


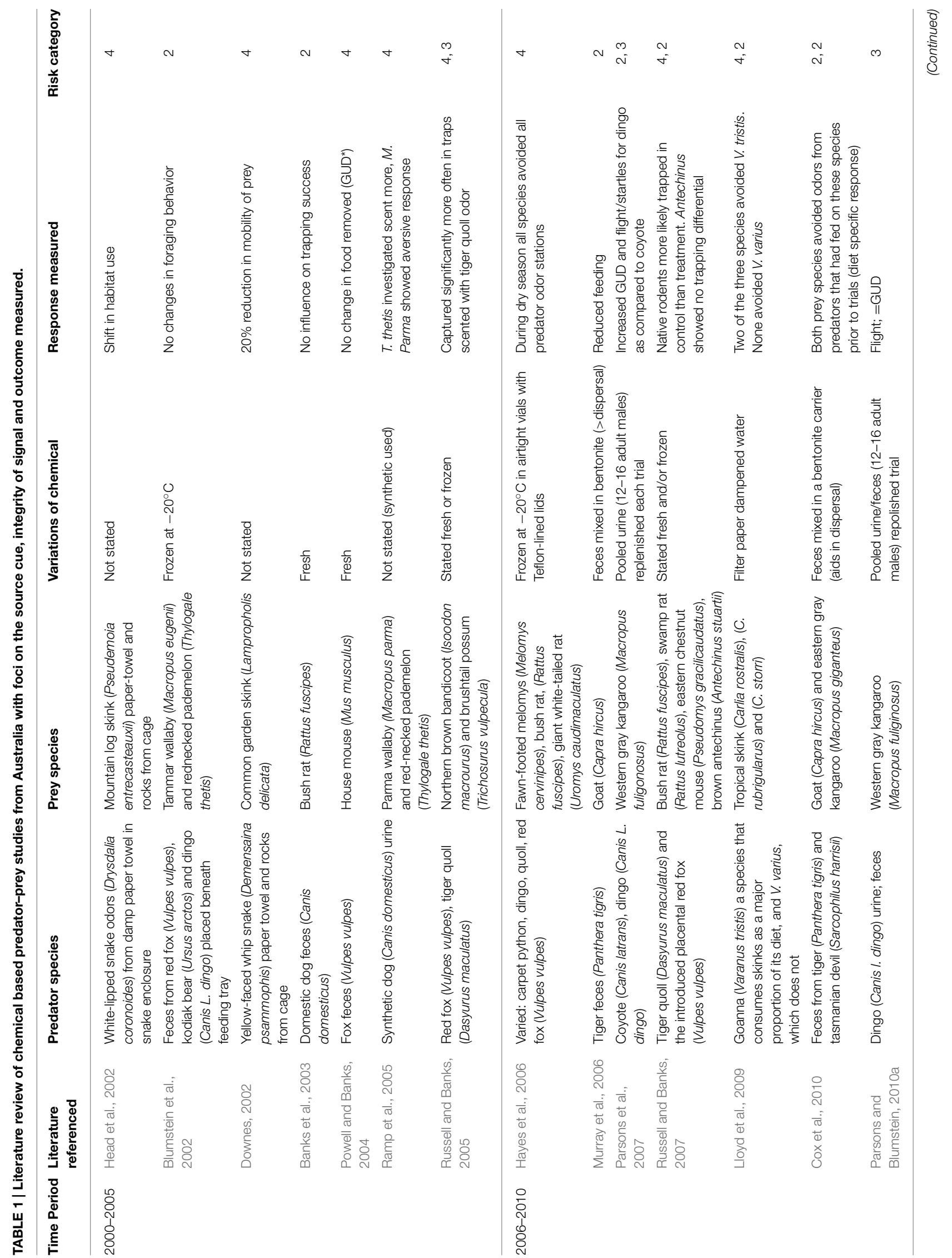




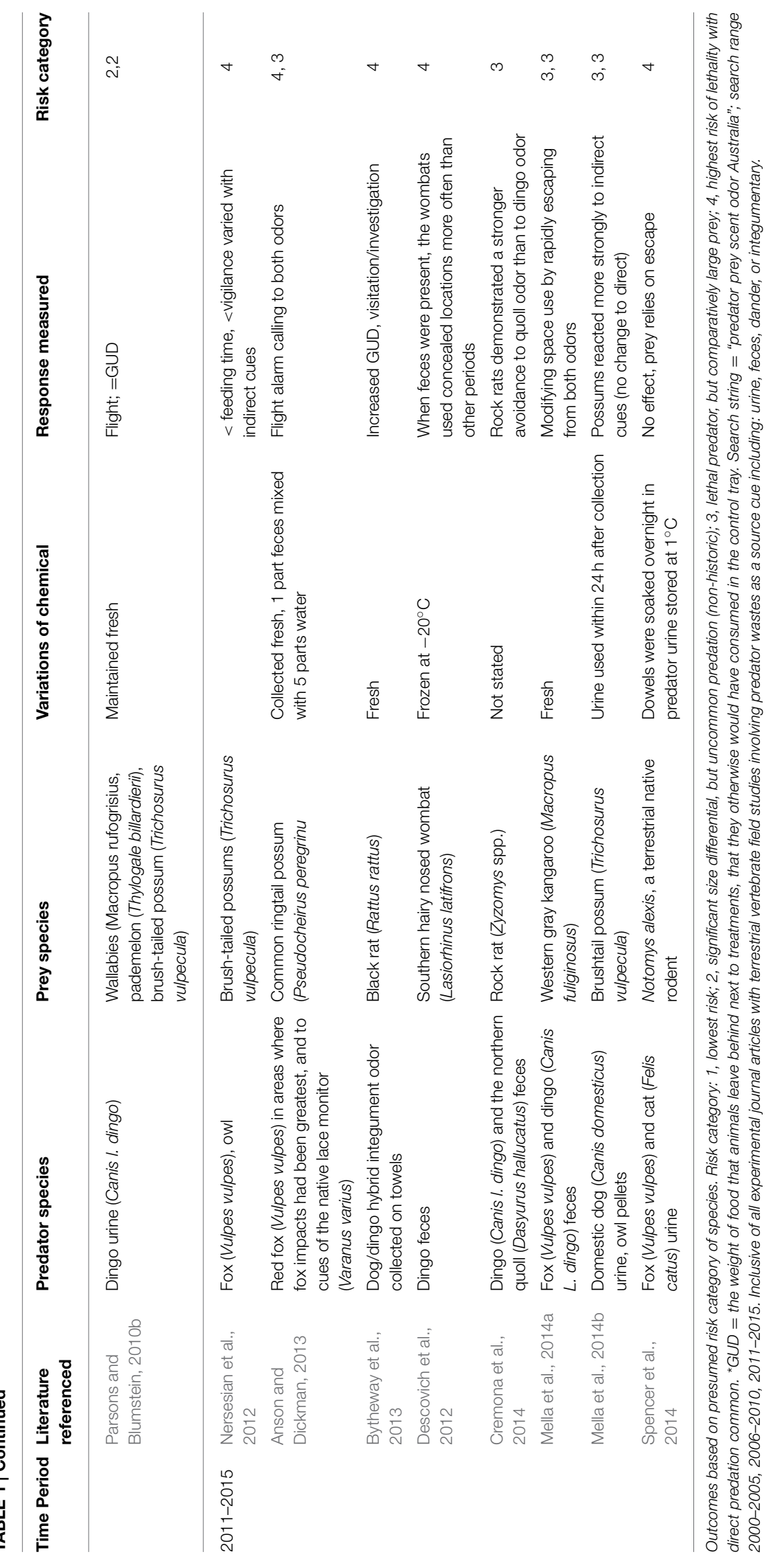


effectiveness of a predator odor to suppress or at least to reduce the reproduction success of potential prey species.

In our review the seminal discussion centers mainly on two questions: (1) is just one single volatile compound in, for example, urine or feces emitted by the predator enough to release defensive reactions in a potential prey species-or must there be a whole profile of odors? (2) Do prey animals respond innately to olfactory predator cues? Our focus is set mainly on mammals, but other vertebrates and lower taxa will be included on some occasions.

\section{Composition and Aging of Olfactory Signals}

An odorant is a chemical compound that gives a particular smell to a source. An odor is typically viewed as a volatile molecule, or a set of molecules, that convey some information about the sender to a receiver; generally, the molecules meeting this specification have molecular weights lower than $300 \mathrm{Da}$.

In mammals, there are different bodily odor sources. Besides urinary odors, other odors emitted from other sources by an animal may serve in the behavioral context to convey information such as degree of hunger or satiety, single, or multiple predators (from over-marking) and importantly, the size, and specificity of the predator- especially important to prey that are otherwise large enough or elusive enough to live comfortably among predators that convey little risk. Among those are anal gland secretions, fecal odors, and vaginal secretions, just to mention the most obvious ones. Fur, dander, sebum, saliva, and tears can also transmit "infochemicals." Some species possess additional glands like the preorbital glands and tarsal organs in many hoofed animals or the supplementary sacculi (located at the opening of the cheek pouches) and the midventral gland of dwarf hamsters (Phodopus spec.) secreting substances of relevance for intraspecific communication.

In invertebrates, just one molecular entity is often sufficient to transmit an important message from one individual to another; the best known example is the pheromone bombykol produced by the silkworm Bombyx mori (Schneider et al., 1968; Kaissling, 2014). Among insects, pheromones (intraspecific messengers) are typically composed of one or only very few molecular types such as hydrocarbons in insect cuticles (Blomquist and Bagnères, 2010), while most odorous substances secreted by mammals are typically composed of numerous different volatile compounds. Depending on the species, up to 70 or more volatile compounds have been found. For example, in ferret (Mustela putorius furo) urine, 31 volatile urinary compounds have been identified and compared with 26 anal gland compounds of the same species. Only 10 compounds were found common to both sources (Zhang et al., 2005). The two marking sources likely convey different messages to conspecifics. This possibility is backed by our observations on wild living ferrets and polecats (Mustela putorius). Males and females urinate all over their territories, but defecate only on specific spots. While urine and fecal odors have putative functions in intraspecific communication, the secretions of the anal glands (containing high amounts of sulfur compounds) seem to serve a dual purpose for defense: when cornered or threatened, and as "alarm pheromones" to warn conspecifics of imminent danger. Two simple compounds from the peri-anal gland, 4-methylpentanal and hexenal, function together as the alarm pheromone in Norway rats (Rattus norvegicus) (Inagaki et al., 2014). These two molecules lose their function, when acting alone.

The composition of the urine odors and possibly also of the anal gland odors may change during the seasons in accordance with the endocrine status and also the diet consumed by a predator. This was seen in the elevated seasonal levels of isopentyl methyl sulfide in the red fox urine (Bailey et al., 1980). Several volatile compounds showed peak levels also in the wolf urine (Canis lupus) depending on the season. These included isopentyl methyl sulfide and several carbonyl compounds (Raymer et al., 1984). Hormone treatment experiments later confirmed that testosterone increased wolf urinary volatile compound levels (Raymer et al., 1986).

Volatile compounds in urine or in a secretion differ in molecular weights and physicochemical properties, such as boiling points, vapor pressure, and solubility properties in water. For instance, in the ferret urine (Zhang et al., 2005) the molecular weight of the individual molecules ranged from 60.05 $\mathrm{Da}$ (acetic acid; boiling point: $118^{\circ} \mathrm{C}$; vapor pressure: $1290 \mathrm{~Pa}$ ) to 256.42 $\mathrm{Da}$ (hexadecanoic acid; boiling point: $215^{\circ} \mathrm{C}$; vapor pressure: $0.5 \times 10^{-4} \mathrm{~Pa}$ ). In the urine of another carnivore (Osada et al., 2013), the wolf (Canis lupus), the molecular weight range extends from $62.13 \mathrm{Da}$ (dimethyl sulfide; boiling point: $35^{\circ} \mathrm{C}$; vapor pressure $53,700 \mathrm{~Pa}$ ) to $122.12 \mathrm{Da}$ (benzoic acid; boiling point: $249^{\circ} \mathrm{C}$; vapor pressure $0.1 \mathrm{~Pa}$ ). In general, compounds with low molecular weights, low polarity, and high vapor pressure evaporate faster than the "heavier," more polar compounds with low vapor pressure properties. These differences might explain why over time the composition of a secretion changes. We will call it "aging of a signal." In this context, aging can mean decreased concentrations or a loss of some components and/or changing ratios between the compounds. This process would be particularly prominent in the arid conditions of Australia, where all compounds, regardless of molecular weight, evaporate more quickly due to increasing of vapor pressures at elevated environmental temperatures. Another consideration is the water solubility of the compound in environmental conditions. Compounds with low water solubility will be less affected by rain and therefore might resist environmental stress much longer than compounds with high water solubility. The much less volatile components of urinary marks and secretions, such as lipids and proteins, may also retain and slowly release volatile chemosignals into the environment.

The numbers of research papers on aging of urine or gland secretion odor compounds are very limited. In contrast to studies on chemical signals in animals, aging has been intensively investigated in food chemistry and interesting results have been reported. For instance, the flavor characteristics of beer appear to deteriorate greatly with time (Gijs et al., 2002). Similarly, changes in some volatile constituents of brandy (Onishi et al., 1977) and sherry wines have been reported (Munoz et al., 2007). Among the first to report on behavioral effects of aged urine were 
Coppola and Vandenbergh (1985). These authors determined how long the puberty delay causing chemosignal emitted from an adult female mouse urine remains active to suppress puberty in young females. According to their data, within 7-10 days after collecting urine, the sample will lose its pheromonal potency to delay puberty in recipient females. The authors suspected that the puberty delay causing signal would lose its potency more rapidly in nature than under laboratory conditions due to the destructive influences of the natural elements.

Neuroendocrine and behavioral responses of mice to urine samples from conspecific males and females, which had aged for different time periods, revealed that the quality and intensity of signaling molecules in urine changed over time (Kwak et al., 2013a). In another study, volatile organic compounds in fresh and aged human urine samples were analyzed and compared (Kwak et al., 2013b).

Due to such unpredictable environmentally-induced changes, researchers run experiments with either fresh secretions or with secretions which were deep-frozen until use. Yet, in spite of deep freezing, the secretions can still undergo composition or conformational changes. This has been convincingly demonstrated in a very recent study during which cat feces was stored at $-70^{\circ} \mathrm{C}$ (Hegab et al., 2014). The statement of these researches reports best the effects of aged chemicals: "Behavioral and hormonal responses and changes in the level of medial hypothalamic c-fos nRNA were examined in Brandt's voles (Lasiopodomys brandtii) exposed to the feces of a domestic cat (Felis catus) stored for different periods. One hundred voles were tested in the defensive withdrawal apparatus. The voles showed an aversion to freshly collected cat feces, indicated by high levels of flight-related behaviors, increased freezing behavior, and more vigilant rearing compared to old feces. The serum levels of adrenocorticotropic hormone and corticosterone significantly increased when the voles were exposed to fresh cat feces. The level of c-fos mRNA in the medial hypothalamus region was highest in the individual exposed to fresh cat feces. All these behavioral, endocrine, and c-fos-mRNA responses were lower when voles were subject to older cat feces" (Hegab et al., 2014). In a study working with meerkats (Suricata suricatta), similar results were found. The freshness of the presented wolf (Canis lupus) urine increased vigilance in the prey animals while the increased quantity of urine sample did not cause the similar effect (Zöttl et al., 2013). Similarly, in comparisons of the effects of fresh and previously frozen female mouse urine on male mice, fresh urine triggered stronger courtship ultrasonic vocalization in males (Hoffmann et al., 2009). Gas chromatographic analyses of dingo urine convincingly demonstrated changes in the male and female urine after an aging period of about 3 months or even less (Figure 1).

Data from such studies indicate that very careful experimentation and interpretation of the data is needed when stored biological compounds are used to study behavioral and physiological parameters. It cannot be excluded that in natural environments, loss of response to a predator odor over time is not caused by habituation, but rather aging of the signal.

\section{Single Odors or Odor Arrays?}

Sensing the chemical warnings present in the environment is essential for species survival. Brunswik (1956) suggested the concept of a transient fear scent operating in mice. Emitted by both males and females, this fear scent can be elicited by a single stressful event. In the natural setting, a mouse's tendency to withdraw from sites possessing the fear scent of conspecifics may well-protect mice from predators and other dangerous situations. Similarly, Carr et al. $(1970,1971)$ reported that male mice avoided an olfactory signal emitted by stressed male and female mice. It was also demonstrated that male mice were repelled by the odor from shocked males and attracted to the odor from non-shocked males (Colyer (1971). Although additional odor sources may be involved, it is believed that a fear scent is contained in the urine (Müller-Velten, 1966). These findings marked the beginning of considering urine as a transmitter of danger odor signals.

Nolte et al. (1994) suspected that predator odors are aversive to prey species due to the high concentrations of sulfurous components (metabolites of protein digestion) in their urine. As reported above, urine or fecal odors are composed of numerous different compounds. Subsequently, many studies in behavioral research have used such complex mixtures and reported the results under these conditions. It is not in the interest of a predator to deposit a signal that persists over longer time periods to warn potential prey about predator's presence. While there is a trade-off involved when predators deploy odors in the environment, it is beneficial for conspecifics to be able to detect these "chemical bulletin boards" for as long as possible. However, the longer the scent is viable, the more likely potential prey could intercept the signal and will respond innately to these kairomones (chemical messages of another species) or will learn to recognize and respond accordingly to these signals. Cheetahs may have evolved the ability to secrete an odorless (elemental) sulfur complex (Burger et al., 2006). On the other hand, secretions may inform conspecifics about a territory owner or a sexual partner ready to mate. In this case, it would be advantageous for the sender when the chemical signal remains in place for a longer time period.

Most mammals were long assumed to have two olfactory systems working independently, the primary olfactory epithelial tissue (MOE) and secondary vomeronasal mediated system (VMO; e.g., pheromones), with the molecular weight of volatile constituents determining the appropriate binding site. This model seemed to have been validated in mice (Trinh and Storm, 2003), but has been since updated to consider the shared role of both organs, now seen to complement one another due to common V1R receptors, and shared processing regions in the amygdala (Kendrick, 2014).

It remains unclear whether single molecule constituents are more or less likely to be received by the primary or secondary systems, than composite chemicals. However, we may operate under the reasonable assumption that predator-secreted compounds are more likely to be detected by the VMO, than foul smelling, or pungent, artificial odors such as diesel fuel, ammonia or feces from non-predatory omnivores (e.g., pigs). These foul odors would contribute less biologically meaningful 


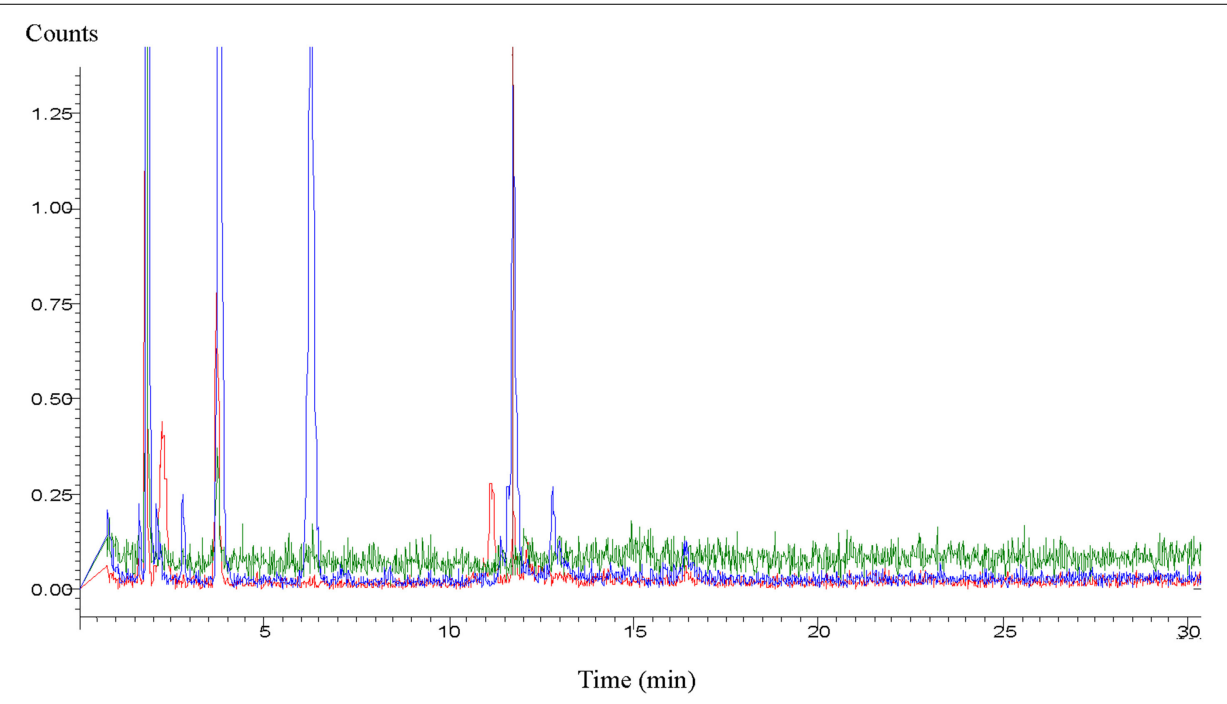

FIGURE 1 | Aged profile of dingo (Canis lupus dingo) urine. Blue loop refers to fresh male urine, red loop refers to fresh female urine, and green loop refers to male and female urine aged $>3$ months (Graph supplied by M.H. Parsons).

information and would thus be more likely to be interpreted by the MOE.

In vertebrates, at least in mammals, generally no single compound is known to convey complex behavioral messages between individuals. Yet, examples that a "bouquet" of odors makes up the message, have been reported with red fox (Whitten et al., 1980) and mice (Jemiolo et al., 1986; Novotny et al., 1986; Ma et al., 1998). However, several papers state that some compounds in urine or fecal secretions are especially effective and will alone, or in combination with other molecules, elicit defensive reactions in prey species and/or suppress breeding success. Some of the four most discussed molecular types include:

(1) Pyrazines are known as volatile nitrogen-containing odoriferous compounds present in vertebrates, plants, insects, fungi, and bacteria (Woolfson and Rothschild, 1990). Pyrazines, such as 2,5-dimethylpyrazine (2,5-DMP), seem to have redundant message contents in vertebrates. In the female mouse urine, 2,5-DMP is involved in a puberty inhibition signaling from a female mouse to other female mice together with five other adrenal-mediated urinary metabolites (Andreolini et al., 1987; Ma et al., 1998).

Male wolf (Canis lupus) urine samples contained more than 50 compounds in the GC-MS analyses with some significant differences in compound levels (Osada et al., 2013). Such differences may allow, for instance, individual recognition within a wolf pack. However, the urine of all three wolfs contained pyrazine derivatives as the predominant active components capable to induce avoidance and freezing behaviors in mice. Osada further reported that the combination of 2,5-DMP and two other pyrazines, which are present in the wolf urine, induced freezing behavior in mice, which was a similar response as to wolf urine, while each pyrazine compound alone was inactive. In the ferret urine, pyrazines could play a role in the odor-sensing and caution expressed by hamsters to the ferret urine (Apfelbach et al., 2015).

(2) 2-Phenylethylamine (PEA) (molecular weight, Mw: 121.18) is a component common to many carnivore odors. It also has been found in non-carnivorous species at much lower concentrations (Ferrero et al., 2011). Like pyrazines it is a moderately volatile compound (vapor pressure $35 \mathrm{~Pa}$, Mokbel et al., 2009), therefore, probably not very effective over longer periods of time. In behavioral studies, rodents avoided a PEA odor source similarly as they avoided predator urines. To verify that PEA is the decisive chemical for the avoiding reaction, the researchers experimentally depleted lion urine of this compound. In the subsequent behavioral experiments, rats showed significant avoidance behavior to $10 \%$ content in lion urine, but not to $10 \%$ PEA-depleted urine specimen. Aversion was fully restored to a 10\% PEArespiked lion urine. The authors interpret from these data that PEA is a key component of a carnivore odor blend detected and avoided by rodents (Ferrero et al., 2011). However, studies under natural conditions have not been reported.

(3) 2,3,5-Trimethyl-3-thiazoline (TMT) (Mw: 129.22) is found in fox feces (Vernet-Maury, 1980). Over the years, several laboratories reported fear-like alterations in rat behavior due to exposure to synthesized TMT (e.g., Wallace and Rosen, 2000). Physiological data as well as data on brain structures involved in the TMT-elicited defensive responses of rats have been also described (Fendt et al., 2003, 2005; Endres et al., 2005; Dielenberg et al., 2001). The view of TMT as a biologically relevant olfactory stimulus has been challenged. According to Morrow (Morrow et al., 2002), a fear-like biochemical and behavioral response in rats to TMT odor depends on the exposure environment. Others have even failed to observe fearful behaviors (McGregor et al., 2002); since TMT has an acrid, irritating, and powerfully repugnant 
odor (at least to humans), its effects are more characteristic of an aversive odor, presumably working through a nociceptive mechanism. According to Staples and McGregor (2006), differences in response to TMT and cat odor could depend on the rat strain.

Blanchard regarded TMT as follows: "These findings suggest that flight/avoidance, although it obviously may occur as one component of a full pattern of defensive and emotional behaviors, is also somewhat separable from the others. When - as appears to be the case with TMT-it is the major, perhaps only consistent defensive behavior elicited, this may reflect a stimulus that is aversive or noxious but with little ability to predict the presence of threat or danger" (Blanchard et al., 2003). To address this criticism, rats were exposed to TMT following either olfactory bulb removal or trigeminal nerve transection (Ayers et al., 2013). The findings indicate that freezing behavior to TMT requires an intact olfactory system, as indicated by the loss of freezing following olfactory bulb removal. Rats with trigeminal nerve transection freeze normally to TMT, suggesting the olfactory system mediates this behavior to TMT. TMT is an ecologically relevant predator odor useful in experiments of unconditioned fear that is mediated via olfaction and not nociception (Ayers et al., 2013).

Very few behavioral field experiments using TMT as a repellent have been reported. To reduce feeding damage by voles (Microtus spec.) on apple trees in orchards Sullivan et al. (1988a) applied TMT to traps and quantified the number of voles caught in TMT-free traps and in traps scented with TMT. The animals significantly avoided the TMT scented traps. In a similar field experiment using Northern pocket gophers (Thomomys talpoides) animals also avoided the TMT odor (Sullivan et al., 1988b). However, when testing the two synthetic predator odors TMT and DMDIT (3,3-dimethyl-1,2-dithiolane) for their possible repelling effects on roof rats (Rattus rattus) in Hawaiian macademia nut orchards no clear results became visible. The authors (Burwash et al., 1998) stated "overall we could not detect significant differences or consistent trends in response of rats to DMDIT or TMT in these field trials."

Without doubt TMT is effective in eliciting fear and escape responses in rats, although they were naive to foxes and fox feces. Interestingly, TMT has not been found in dog feces (Arnould et al., 1998) and also not in anal gland secretions of dog and coyote (Preti et al., 1976), although both carnivore species are closely related to the red fox. These and other results indicate that TMT may be characteristic for the red fox, but possibly not for other predators.

(4) A cat-specific substance is 2-amino-7-hydroxy-5,5dimethyl-4-thiaheptanoic acid (L-felinine) (MW: 207.29). Felinine, a putative pheromone precursor, has been identified in the urine of several members of the felidae family including the domestic cat (Felis catus) (Hendriks et al., 1995b). Cat urine contains 3-mercapto-3methylbutan-1-ol, a degradation product of felinine, and a putative cat pheromone. This compound gives cat urine its typical odor and may have a function in territorial marking
(Hendriks et al., 1995a; Miyazaki et al., 2006). However, no experimental proof has been provided up to date for this assumption. Felinine is a non-volatile amino acid that requires a close contact ("close contact signal") for the olfactory perception. To investigate the influence of cat odor on reproductive behavior and physiology in the house mouse, cat urine or $0.05 \%$ felinine was directly applied to the bedding of pregnant mice every other day. After having given birth, the total number of offspring was counted as well as the number of pups per female. Exposure of mated females to felinine provoked a pregnancy block in $67.85 \%$ female mice, while in the control group a birth reduction of only $17.86 \%$ was observed (Voznessenskaya, 2014). Felinine has not been tested outside the laboratory conditions so far.

Rats and mice are averse to the odor of a cat's urine, but after they are infected with the parasite Toxoplasma gondii, they are attracted to cat urine. This increases the likelihood of being preyed upon and consequently, infecting the cat (Berdoy et al., 2000). Earlier, a similar decrease in predator avoidance in parasitized mice was reported. Mice infected with the naturally occurring Eimeria vermiformis spent a significantly longer time period in the proximity of cat odor, while uninfected mice continued to avoid cat urine. This result indicates that infection with $E$. vermiformis in mice reduces the avoidance of a predator odor through neurochemical systems associated with anxiety involving GABA receptor mechanisms (Kavaliers and Colwell, 1995).

Besides felinine odor, cats emit other chemical signals. Cats mark their territories by rubbing their neck at corners or objects leaving a scent behind ("cat neck odor"). When a rat is exposed to such a scent, it exhibits a strong aversive/flight reaction. When Wistar rats were exposed to a cotton pad wiped on a cat body rubbing location, they showed increased hiding behavior, decreased exploration behavior and reduced stimulus approach and investigation. These defensive responses persisted for up to 4 days following a single stimulus exposure (May et al., 2012). C-fos studies revealed a high activation of the brain structures involved in these fear reactions (Dielenberg et al., 2001). So far no information is published about the compound responsible for the reported behavioral effects.

It may seem unlikely that only one type of a volatile molecule out of the many compounds (e.g., in urine) is sufficient for eliciting escape or defense reactions in a prey. Considering the above findings, one can conclude that the amount of information encoded in one urinary volatile molecule seems limited. The predator odor information system may act more like a "yesno" (danger-no danger) information system. Much more information can be encoded in a "bouquet" of several volatile compounds. Already in 1994, Nolte and coworkers reported that herbivorous rodents were able to distinguish between urine collected from coyotes fed cantaloupes vs. those fed a meat diet. Similarly, in a paper by Berton et al. (1998), the authors demonstrated that mice were able to distinguish between the fecal odor of cats subjected to either a vegetarian diet or a carnivorous diet. In a recent study, it was demonstrated that the dwarf hamster (Phodopus campbelli) was able to readily distinguish 
between urine of ferrets fed with chicken, rat, or hamster. While dietary variations are unlikely to result in measurable quantities of additional urinary compounds, the signal-receiving animals may be capable of distinguishing quantitative differences in the urinary volatile compound arrays (shown in Figure 2), and subsequently, perceiving different olfactory messages (Apfelbach et al., 2015).

An interesting question is how fast naïve animals are able to learn to respond to odors of a new, previously unknown predator. Anson and Dickman (2013) explored in a field study the ability of the common ringtail possum (Pseudocheirus peregrinus), a semi-arboreal Australian marsupial, to recognize and respond to olfactory cues from the introduced fox (Vulpes vulpes). Their results show that in the areas with high fox densities, the selection pressure from the fox has been sufficient for ringtails to develop anti-predator behaviors over a few generations

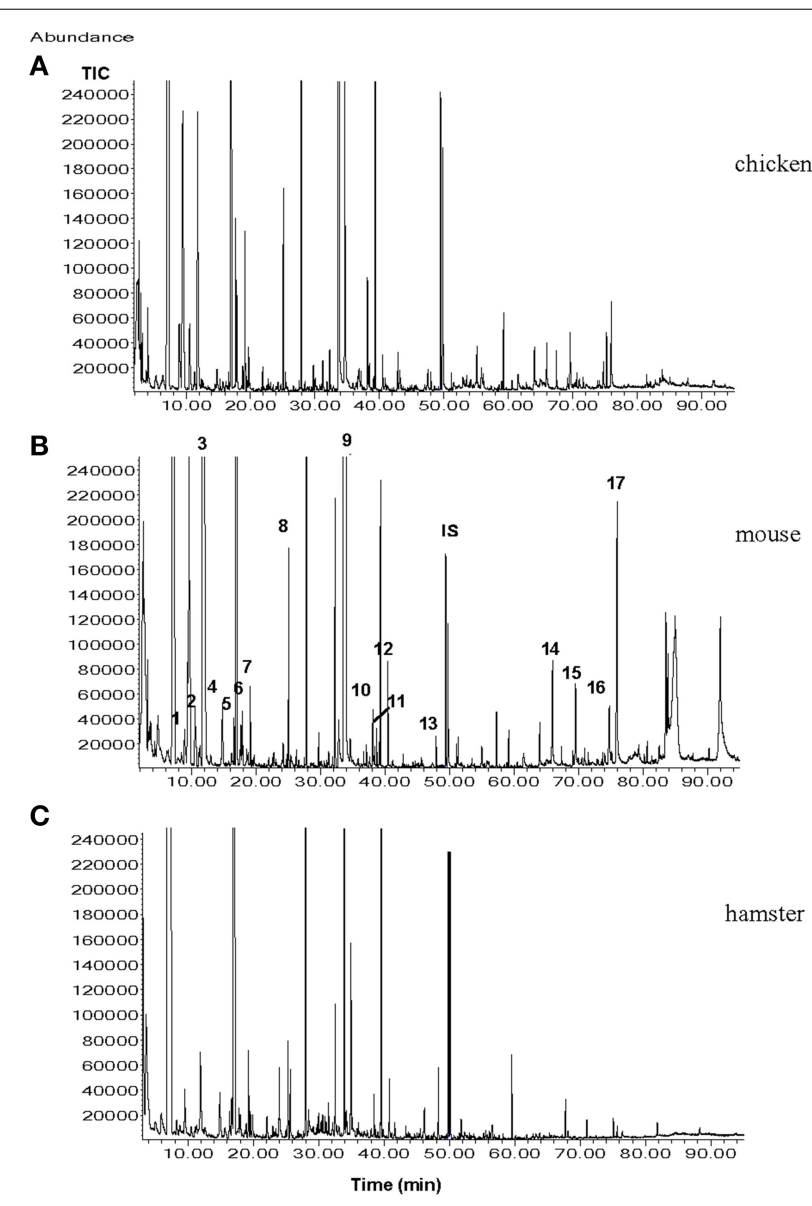

FIGURE 2 | Total ion chromatograms (TICs) from the male ferret urine samples when ferrets were fed with (A), chicken; (B), mouse; (C), hamster. Numbers indicate the following compounds 1, xylene; 2, heptanal; 3, 2,5-dimethylpyrazine; 4, benzaldehyde; 5, 6-methyl-5-hepten-2-one; 6, 2,3,5-trimethylpyrazine; 7, 2-ethenyl-6-methylpyrazine; 8, non-anal; 9 , quinoline; 10, o-aminoacetophenone; 11, 2-methylquinoline; 12 ,

2-methylquinazoline; 13, geranylacetone; 14, tetradecanoic acid; 15 , pentadecanoic acid; 16, 9-hexadecanoic acid; 17, hexadecanoic acid; IS internal standard (7-tridecanone) (Graph taken from Apfelbach et al., 2015). since foxes had become established in the area. In contrast to this finding, no such anti-predator behavior patterns were obvious in the areas where foxes either had not been observed or observed only very recently. A recent paper by Dias and Ressler (2014) will likely receive considerable attention among scientists. These authors examined the inheritance of a parental traumatic olfactory exposure. F0 mice were subject to odor fear conditioning before conception, and subsequently in F1 and F2 generations, an increased behavioral sensitivity to the F0-conditioned odor, acetophenone, but not to other odors, was found. Besides behavioral studies, neuroanatomical, and genetic studies including cross-fostering were employed. Taking all their data into account, the authors concluded that their findings provide a framework for addressing how environmental information may be inherited transgenerationally at behavioral, neuroanatomical, and epigenetic levels.

\section{Field Studies in Australia-A Unique Experimental Field}

Australia offers a unique opportunity to observe the relationship between predator-naïve native marsupial prey species of various size and introduced placental predators. This situation allows experiments under natural conditions to follow the question whether predator odors will be ignored or investigated or do they elicit aversive reactions. Researchers have accumulated an enormous amount of data exploring the effects of eutherian predator odors on native marsupial mammals. Some of these data will be included in our review.

The introduction of alien predators often has catastrophic effects on populations of native prey species. Australia offers a unique opportunity to observe the relationship between predator-naïve native prey species of various size and introduced predators. It is a challenge to investigate the "evolution" of a balanced relationship between newcomers and endemic species when there is no consensus on how long predator and prey must remain together in order to co-adapt.

For thousands of years, the dingo was the only eutherian predator well-embedded in the Australian food chain. With the arrival of the Europeans in Australia, previously unknown predator species also arrived at this isolated continent. Predators such as the European fox (Vulpes vulpes), the feral cat (Felis catus), wild dogs (Canis lupus familiaris), coyotes (Canis latrans), and ferrets (Mustela putorius furo) established themselves and started to threaten naïve native species. Correspondingly, quite a high number of field studies have been reported from Australia. In all these studies, complex natural predator odors and no single volatile compounds were employed.

With a few examples, the relationship between predator and prey will be depicted in this section of the review. Special attention is given to the question as to how effective are unknown carnivorous chemicals as repellents to small $(<2 \mathrm{Kg})$, medium sized $(>2 \mathrm{Kg})$ and large prey $(>10 \mathrm{Kg})$ species as compared to their predators. It seems logical that larger prey animals (or those with better defenses or escape ability) respond to a wider variety of chemical signals. Smaller, or more vulnerable, animals 
like murids should fear almost any sulfur-rich or nitrogencontaining odor regardless of the type of predator that produced it. There is a question whether a prey (e.g., a rat) should be more discriminating and should respond to single chemical compounds indicating a feline or canine, or whether a kangaroo should respond to canine, but certainly not, feline compounds. Larger prey, or more capable defenders, may also be more discriminating of additional compounds of the odor, such as the concentration ratio (intensity) of meat metabolites, an honest advertisement that a predator has previously consumed prey.

In situations where a prey survives the initial impact of Europe-originated predators, a predator may act as a strong selective agent for prey to develop strategies to manage predation risk. However, Australian studies on the use of unknown predator odor cues by mammalian prey species produced contradictory results. According to Woolhouse and Morgan (1995), some native species avoid the odors of all predators, but these native species were small and fall into the highest risk category for predation (Table 1, risk category 4). Data published by Nersesian et al. (2012) and Spencer et al. (2014) supported this finding. Other species appear to respond only to odors of native predators (Dickman, 1993). In some cases, native mammals show no evident avoidance of the odors of native and introduced predators (Blumstein et al., 2002).

Since the establishment of foxes to Australia in the 1870s, these predators have been linked to a local loss and regional extinction of several small to medium-sized mammals and some other vertebrates (Burbidge and McKenie, 1989). Two studies should be particularly emphasized. In 1998, Banks reported on the responses of wild Australian bush rats (Rattus fuscipes) to the odor (fresh feces tainted with the urine) of the European fox (Vulpes vulpes). Trapping success of rats was compared between clean traps and traps scented with fox odor in winter, spring, and summer. Trapping success was statistically analyzed and no difference between scented and unscented traps was found. Bush rats behaved naïvely toward the predator odor (Banks, 1998). In a similar second study, Banks et al. (2003) analyzed trapping success again using bush rats, with traps scented with dog feces and unscented traps. Bush rats showed no aversion to dog fecal odors and entered unscented and dog-scented traps equally. The researchers concluded that this lack of response may be because rats do not identify fox or dog scats as a cue to predation risk. However, another interpretation for these findings was that animals may have been startled (fled) into traps instead of away from them (a common occurrence that has been corroborated by video evidence), and thus trap-presence should not be a clear indicator for lack of vigilance. This is because animals are often recruited toward a scent in order to investigate additional scentrelated information. In another field study (Anson and Dickman, 2013), behavior and in addition glucocorticoid hormone levels were analyzed on the marsupial ringtail possum (Pseudocheirus peregrinus). Animals were exposed to fox-suppressed areas and to areas where foxes were abundant. Ringtails showed no physiological or behavioral differences between the two areas. This lack of response to the fox odor may represent complete naivité or strong rapid selection to the invasive predator. Or, based on the relative risks posed by a predator relative to the size of prey, it could reflect the animal's category of risk. For instance, ringtail possums are capable defenders and fit within category 3 (lethal predator but uncommon predation), and would likely require more information such as a composite cue with direct predator presence in the immediate vicinity, or predator cues from a more threatening predator or group of countermarking predators, before retreating from a preferred food patch. All these findings are somehow surprising, since fox feces is a very powerful odor to elicit escape reactions in European rodents. Mice (highest risk of lethality with predation common; category 4) would be more likely to be wary of any predator scent, regardless of the composite nature of timestamp of delivery. Macropods, the largest of the marsupials, would be the most selective in which predator scents to avoid. This may help explain why macropods can differentiate among risks posed by coyotes, domestic dogs, and dingo-with the primary avoidance response being to urine by dingoes.

Kovacs et al. (2012) reported on two common species of Australian small mammals (bush rat, Rattus fuscipes, and brown antechinus, Antechinus stuartii) that have persisted for over a century in the presence of the European fox). No difference in prey abundance in sites with high and low fox activity was found. However, survival of the bush rat was almost two-fold higher where fox activity was low. The conclusion of the authors was that populations of both species perform better where the activity of the predator is low. Interestingly, juvenile, but not adult rats, avoided fox odor on traps more strongly where fox activity was high than where it was low, but neither adult R. fuscipes nor $A$. stuartii responded differently to different levels of fox activity. Avoidance of fox odor declined over time.

In most areas of Australia, kangaroos enter farming areas and compete with farm animals for food, and are the primary selective agent in shaping forest rehabilitation following fire or anthropogenic disturbance, e.g., the kangaroo palate determines the composition of plant rehabilitation. As a consequence of this behavior, researchers have sought methods to influence food patch selection such that kangaroos would leave food patches with vulnerable, moist seedlings in exchange for mature forage that could compensate following herbivory. They tested the effectiveness of the urine of dingoes and non-native predators like coyotes (Canis latrans) to protect farming areas. When they experimentally deployed recent voids of dingo urine, kangaroos (Macropus spp.) were highly aroused and fled, some in excess of $50 \mathrm{~m}$ from the odor source (Parsons and Blumstein, 2010a). When they presented the novel coyote urine, kangaroos (large prey animals category 3) did not flee, but rather investigated the new smell-possibly to determine whether the scent conveyed enough risk to forgoing a feeding opportunity. This experiment was repeated in Tasmania (Parsons and Blumstein, 2010b) where wallabies (Macropus rufogrisius), pademelons (smaller macropods, Thylagale stigmatica) and brushtail possums (Trichosuras vulepcula) had never been exposed to dingoes (category 2). The outcomes, however, were similar in that all three small species (usually in the high risk categories) avoided the dingo scent (Parsons and Blumstein, 2010b). These outcomes may have been influenced because the dingoes had been regularly fed kangaroo carcasses prior to collection. While attempting to 
"synthesize" the urine to assist land rehabilitation, the authors determined that aged urine had completely lost its effectiveness (Figure 1) to such a degree that it could actually be used to attract the same animals the fresh urine had once repelled (Parsons et al., 2012). Again, it is assumed this "attraction" is based on attempts by the discriminating animal to obtain further information to warrant a behavioral response.

Kangaroos are both large in comparison to their predators and mobile, and should have a higher level of confidence that a specific chemical represents tangible risks before making a decision to forgo feeding. Therefore, kangaroos should be more discriminating than smaller mammals. This approach was supported when Cox et al. (2010), who learned that kangaroos were not repelled by carnivorous Tasmanian devils (Sarcophilus harrisii, a small predator); the authors reversed the outcomes: they fed kangaroo meat to Tasmanian devils, and the kangaroos fled.

Interestingly, Cox et al. (2014) were able to generate a similar response from an exotic non-native species, the tiger (Pandera tigris). When fed on kangaroo meat, tiger feces became an effective repellent for kangaroos, sometimes generating an "area-effect." More recently, southern hairy-nosed wombats (Lasiorhinus latifrons) have been found to avoid digging in the area where dingo urine or feces had been deployed. Wombats remained in the area, as indicated by fresh tracks, but chose to dig tunnels in areas farther from dingo odors. Similar experiments with dingo urine were performed in Tasmania. Dingoes never entered Tasmania, but it was found that during the trials with natural dingo urine, supplemented with a gel, $78 \%$ of wallabies and $80 \%$ of possums were repelled (Macey, 2008). The authors again concluded that the smaller prey animals in higher risk categories may have been more sensitive and less discriminating to an unfamiliar predator. Unfortunately, the information about 200 chemical ingredients of dingo urine have not yet been published. Therefore, a comparison with the urine of old world carnivores is not available.

An examination of Table 1 suggests that the only category 2 interactions where a significant prey response was recorded, occurred from exotic-but large or pack-hunting predatorsthe tiger and the dingo. Whereas, 14 of the 18 occasions where category 3 or 4 interactions were inferred related in some level of aversion (Table 1). The remaining variation may be explained by a combination of single molecule deterrents being trialed such as the domestic dog synthetic used by Ramp et al. (2005), unique response variables such as measuring levels of novel food that has been placed in close proximity to the predator odor-where mixed plumes may conflate the identification of each moleculeor the level of preservation of frozen or partly degraded scents.

At least some prey species do not necessarily escape when a predator odor is encountered. This has been very convincingly shown in an open environment with the spinifex hopping-mouse (Notomys alexis), an Australian desert rodent. Spencer et al. (2014) tested the foraging and movement responses of the rodent to non-native predator (fox and cat) urine odor. Urines were collected from a fox just killed prior to urine sampling and stored at $\sim 1^{\circ} \mathrm{C}$ until use; cat urine was obtained from euthanized cats. (Unfortunately no information is given in the paper for how long the urines were stored.) Rodents did not respond to these predator odors as one might have expected. Experience with an unknown predator and the stimuli emitted by the predator are for sure decisive for a balanced interaction between predators and prey (Anson and Dickman, 2013). Even in a fish predator, experience, and feeding history determines prey behavior and survival (Lönnstedt et al., 2012).

\section{Conclusions}

Based on the lessons we have learned from the recent literature, particularly from field trials in Australia, we now have a heightened awareness of the following three factors that may influence reported outcomes:

(1) Complexity of the molecular signal: Several studies have tried to find universal carnivore signals that, when received by a potential prey species, will be adequately responded to, even when the prey species never had encountered that predator or its odor before. Indeed, there are some volatile compounds found in many carnivores that elicit defensive and/or even fear reactions in a prey. Almost any sulfurrich or nitrogen-containing compound elicits such behaviors regardless of the predator source. Generally, these single compounds are not effective alone (except TMT), but require other accompanying molecules to gain efficiency. Most often, single volatile substances convey very limited information about the predator. In contrast, arrays of different volatile compounds may convey more relevant information to the receiver, for example, the type of food the predator has consumed.

(2) Chemical stability of the signal: A major consideration in all predator-prey studies is the stability of the chemical compounds and thus stability of the message. As demonstrated, aging of an odor bouquet could result in a modified information or even loss of the message.

(3) Variable risk posed by the predator as compared to the prey: When evaluating the effectiveness of an odor used as a repellent, the size, and defensive abilities of the prey species has to be taken into account. In particular, Cox et al. (2010) showed that the largest macropods, Eastern gray kangaroos, will ignore recently-voided urine from the non-threatening, small Tasmanian devil. However, this wild-type response (e.g., ignoring small predators) was changed when the risk category was reversed by adding kangaroo meat to the predator diet. And this helped support our position that single molecule scents are less likely to be effective in deterring large herbivores, because larger animals may require more biologically relevant information than what a single molecule can provide. The Australian studies also demonstrate that not all potential prey species respond to unknown carnivore odors (not even to fox feces containing TMT) with defensive behaviors. Obviously they do not identify innately predator scents as a cue to predation risk; some even will show odor exploration behaviors when an unknown odor is presented. However, some species originally ignoring unknown predator odors 
learn to associate such odors over time, especially after the predator has preyed conspecifics.

\section{Acknowledgments}

This review article is the result of a cooperation project between RA (he designed the paper and wrote the first draft),

\section{References}

Albone, E. S., and Perry, G. C. (1975). Anal sac secretion of the red fox, Vulpes vulpes; volatile fatty acids and diamines: implications for a fermentation hypothesis of chemical recognition. J. Chem. Ecol. 2, 101-111. doi: 10.1007/BF00988029

Andersen, K. K., and Bernstein, D. T. (1975). Some chemical constituents of the scent of the striped skunk (Mephitis mephitis). J. Chem. Ecol. 1, 493-499.

Andersen, K. K., Bernstein, D. T., Caret, R. L., and Romanczyk, L. J. Jr. (1982). Chemical constituents of the defensive secretion of the striped skunk (Mephitis mephitis). Tetrahedron 38, 1965-1970. doi: 10.1016/0040-4020(82)80046-X

Andreolini, F., Jemiolo, B., and Novotny, M. V. (1987). Dynamics of excretion of urinary chemosignals in the house mouse (Mus musculus) during the natural estrous cycle. Experientia 43, 998-1002. doi: 10.1007/BF01952217

Anson, J. R., and Dickman, C. R. (2013). Behavioral responses of native prey to disparate predators: naivité and predator recognition. Oecologia 17, 367-377. doi: $10.1007 / \mathrm{s} 00442-012-2424-7$

Apfelbach, R., Blanchard, C. D., Blanchard, R., Hayes, R. A., and McGregor, I. S. (2005). The effects of predator odors in mammalian prey species: a review of field and laboratory studies. Neurosci. Biobehav. Rev. 29, 1123-1144. doi: 10.1016/j.neubiorev.2005.05.005

Apfelbach, R., Soini, H. A., Vasilieva, N. Y., and Novotny, M. V. (2015). Behavioral responses of predator-naïve dwarf hamsters (Phodopus campbelli) to odor cues of the European ferret fed with different prey species. Physiol. Behav. 146, 57-66. doi: 10.1016/j.physbeh.2015.04.014

Arnould, C., Malosse, C., Signoret, J. P., and Descoins, C. (1998). Which chemical constituents from dog feces are involved in its food repellent effect in sheep? Chem. Senses 24, 559-576.

Ayers, L. W., Asok, A., Heyward, F. D., Jeffrey, B., and Rosen, J. B. (2013). Freezing to the predator odor 2,4,5-dihydro-2,5-trimethylthiazoline (TMT) is disrupted by olfactory bulb removal but not trigeminal deafferentation. Behav. Brain Res. 253, 54-59. doi: 10.1016/j.bbr.2013.06.034

Bailey, S., Bunyan, P. J., and Page, M. J. (1980). "Variation in the levels of some components of the volatile fraction of urine from captive red foxes (Vulpes vulpes) and its relationship to the state of the animal," in Chemical Signals: Vertebrates and Aquatic Invertebrates, eds D. Müller-Schwartze and R. M. Silverstein (New York, NY: Plenum Press), 391-404.

Banks, P. B. (1998). Responses of Australian bush rats, Rattus fuscipes, to the odor of introduced Vulpes vulpes. J. Mammal. 79, 1260-1264. doi: 10.2307/1383017

Banks, P. B., Nelika, K., Hughes, K. N., and Rose, T. (2003). Do native Australian small mammals avoid faeces of domestic dogs? Responses of Rattus fuscipes and Antechinus stuartii. Aust. Zool. 32, 406-409. doi: 10.7882/AZ.2002.018

Berdoy, M., Webster, J. P., and MacDonald, D. W. (2000). Fatal attraction in rats infected with Toxoplasma gondii. Proc. Biol. Sci. 267, 1591-1594. doi: 10.1098/rspb.2000.1182

Berton, F., Vogel, E., and Belzung, C. (1998). Modulation of mice anxiety in response to cat odor as a consequence of predator's diet. Physiol. Behav. 65, 247-254. doi: 10.1016/S0031-9384(98)00126-7

Blanchard, D. C., Griebel, G., and Blanchard, R. J. (2003). Conditioning and residual emotionality effects of predator stimuli: some reflections on stress and emotion. Prog. Neuropsychopharmacol. Biol. Psychiatry 27, 1177-1185. doi: 10.1016/j.pnpbp.2003.09.012

Blomquist, G. J., and Bagnères, A.-G. (eds.). (2010). Insect Hydrocarbons. Biology, Biochemistry and Chemical Ecology. Cambridge: Cambridge University Press.

Blumstein, D. T., Mari, M., Daniel, J. C., Ardron, J. G., Griffin, A. S., and Evans, C. S. (2002). Olfactory predator recognition: wallabies may have to learn to be wary. Anim. Conserv. 5, 87-93. doi: 10.1017/S1367943002002123
MP (he added the Australian studies), HS, and MN (both worked and expanded the chemical part of the here presented article). We thank the reviewers for their help to improve the article by suggesting aspects we did not think about. We acknowledge support by the Deutsche Forschungsgemeinschaft and Open Access Publishing Fund of Tübingen University.
Brinck, C., Erlinge, S., and Sandell, M. (1983). Anal sac secretion in mustelids. A comparison. J. Chem. Ecol. 9, 727-744. doi: 10.1007/BF00988779

Brunswik, E. (1956). Perception and Representative Design of Psychological Experiments. Berkeley, CA: University of California Press.

Burbidge, A. A., and McKenie, N. L. (1989). Patterns in the modern decline of Western Australia vertebrate fauna - causes and conservation implications. Biol. Conserv. 50, 143-198. doi: 10.1016/0006-3207(89)90009-8

Burger, B. V., Visser, R., Moses, A., and Le Roux, M. (2006). Elemental sulfur identified in urine of cheetah, Acinonyx jubatus. J. Chem. Ecol. 32, 1347-1352. doi: 10.1007/s10886-006-9056-5

Burwash, M. D., Tobin, M. E., Woolhouse, A. D., and Sullivan, T. P. (1998). Field testing synthetic predator odors for roof rats (Rattus rattus) in Hawaiian Macademia nut orchards. J. Chem Ecol. 24, 603-630. doi: 10.1023/A:1022304917652

Bytheway, J. P., Carthey, A. J., and Banks, P. B. (2013). Risk vs. reward: how predators and prey respond to aging olfactory cues. Behav. Ecol. Sociobiol. 67, 715-725. doi: 10.1007/s00265-013-1494-9

Carr, W. J., Martorano, R. D., and Krames, L. (1970). Response of mice to odors associated with stress. J. Comp. Physiol. Psychol. 71, 223-228. doi: 10.1037/h0029164

Carr, W. J., Roth, P. A., and Amore, M. (1971). Responses of male mice to odors from stressed vs nonstressed males and females. Psychon. Sci. 25, 275-276. doi: 10.3758/BF03335874

Colyer, S. W. (1971). Valence of Stress and Nonstress Index in Odors and the Effectiveness of post Stress Odor Emission in Mice. Unpublished doctoral dissertation, Temple University.

Coppola, D. M., and Vandenbergh, J. G. (1985). Effect of density, duration of grouping and age of urine stimulus on the puberty delay pheromone in female mice. J. Reprod. Fertil. 73, 517-522. doi: 10.1530/jrf.0.0730517

Cox, T. E., Murray, P. J., Bengsen, A. J., Hall, G. P., and Li, X. (2014). Do fecal odors from native and non-native predators cause a habitat shift among macropods? Wildl. Soc. Bull. 39, 159-164. doi: 10.1002/wsb.509

Cox, T. E., Murray, P. J., Hall, G. P., and Li, X. (2010). Pest responses to odors from predators fed a diet of target species conspecifics and heterospecifics. J. Wildl. Manag. 74, 1737-1744. doi: 10.2193/2009-410

Cremona, T., Crowther, M. S., and Webb, J. K. (2014). Variation of prey responses to cues from a mesopredator and an apex predator. Aust. Ecol. 39, 749-754. doi: $10.1111 /$ aec. 12138

Crump, D. R. (1980). Anal gland secretion of the ferret. J. Chem. Ecol. 6, 837-844. doi: $10.1007 / \mathrm{BF} 00990407$

Crump, D. R., and Moors, P. J. (1985). Anal gland secretions of the stoat (Mustela ermine) and the ferret (Mustela putorius forma furo). Some additional thietane components. J. Chem. Ecol. 11, 1037-1043. doi: 10.1007/BF01020673

Derby, C. D., and Aggio, J. F. (2011). The neuroecology of chemical defenses. Int. Comp. Biol. 51, 771-780. doi: 10.1093/icb/icr063

Descovich, K. A., Lisle, A. T., Johnston, S., Nicolson, V., and Phillips, C. J. (2012). Differential responses of captive southern hairy-nosed wombats (Lasiorhinus latifrons) to the presence of faeces from different species and male and female conspecifics. Appl. Anim. Behav. Sci. 138, 110-117. doi: 10.1016/j.applanim.2012.01.017

Dias, B. G., and Ressler, K. J. (2014). Parental olfactory experience influences behavior and neural structure in subsequent generations. Nat. Neurosci. 17, 89-96. doi: 10.1038/nn.3594

Dickman, C. R. (1993). Raiders of the last ark: cats in island Australia. Aust. Nat. Hist. 24, 44-52.

Dielenberg, R. A., Hunt, G. E., and MacGregor, I. S. (2001). "When a rat smells a cat": the distribution of Fos immunoreactivity in rat brain following 
exposure to a predator odor. Neuroscience 104, 1085-1097. doi: 10.1016/S03064522(01)00150-6

Downes, S. J. (2002). Does responsiveness to predator scents affect lizard survivorship? Behav. Ecol. Sociobiol. 52, 38-42. doi: 10.1007/s00265-002-0477-z

Endres, T., Apfelbach, R., and Fendt, M. (2005). Behavioral changes induced in rats by exposure to trimethylthiazoline, a component of fox odor. Behav. Neurosci. 119, 1004-1010. doi: 10.1037/0735-7044.119.4.1004

Engelhart, A., and Müller-Schwarze, D. (1995). Responses of beaver (Castor canadensis Kuhl) to predator chemicals. J. Chem. Ecol. 21, 1349-1364. doi: 10.1007/BF02027567

Fendt, M., Endres, T., and Apfelbach, R. (2003). Temporary inactivation of the bed nucleus of the stria terminalis but not of the amygdala blocks freezing induced by trimethylthiazoline, a component of fox feces. J. Neurosci. 23, 23-28.

Fendt, M., Endres, T., Lowry, C. A., Apfelbach, R., and McGregor, I. S. (2005).TMT-induced autonomic and behavioral changes and the neural basis of its processing. Neurosci. Biobehav. Rev. 29, 1145-1156. doi: 10.1016/j.neubiorev.2005.04.018

Ferrero, D. M., Lemon, J. K., Fluegge, D., Pashkovski, S. L., Korzan, W. J., Datta, S. R., et al. (2011). Detection and avoidance of a carnivore odor by prey. Proc. Natl. Acad. Sci. U.S.A. 108, 11235-11240. doi: 10.1073/pnas.1103317108

Gijs, L., Chevance, F., Jerkovic, V., and Collin, S. (2002). How low pH can intensify $\beta$-damascenone and dimethyltrisulfide production through beer aging. J. Agric. Food Chem. 50, 5612-5616 doi: 10.1021/jf020563p

Hayes, R. A., Nahrung, H. F., and Wilson, J. C. (2006). The response of native Australian rodents to predator odours varies seasonally: a by-product of life history variation? Anim. Behav. 71, 1307-1314. doi: 10.1016/j.anbehav.2005.08.017

Head, M. L., Keogh, J. S., and Doughty, P. (2002). Experimental evidence of an age-specific shift in chemical detection of predators in a lizard. J. Chem. Ecol. 28, 541-554. doi: 10.1023/A:1014592028693

Hegab, I. M., Jin, Y., Ye, M., Wang, A., Yin, B., Yang, S., et al. (2014). Defensive responses of Brandt's voles (Lasiopodomys brandtii) to stored cat feces. Physiol. Behav. 123, 193-199. doi: 10.1016/j.physbeh.2013.10.030

Hendriks, W. H., Moughan, P. J., Tarttelin, M. F., and Woolhouse, A. D. (1995b). Felinine: a urinary amino acid of felidae. Comp. Biochem. Physiol. B Biochem. Mol. Biol. 112, 581-588. doi: 10.1016/0305-0491(95)00130-1

Hendriks, W. H., Tarttelin, M. E., and Moughan, P. J. (1995a). Twenty-four hour felinine (corrected) excretion patterns in entire and castrated cats. Physiol. Behav. 58, 467-469. doi: 10.1016/0031-9384(95)00084-V

Hoffmann, F., Musolf, K., and Penn, D. J. (2009). Freezing urine reduces its efficacy for eliciting ultrasonic vocalizations from male mice. Physiol. Behav. 96, 602-605. doi: 10.1016/j.physbeh.2008.12.014

Inagaki, H., Kiyokawa, Y., Tamogami, S., Watanabe, H., Takeuchi, Y., and Mori, Y. (2014). Identification of a pheromone that increases anxiety in rats. Proc. Nat. Acad. Sci. U.S.A. 111, 18751-18756. doi: 10.1073/pnas.14147 10112

Jemiolo, M., Harvey, S., and Novotny, M. V. (1986). Promotion of the Whitten effect in female mice by synthetic analogs of male urinary constituents. Proc. Natl. Acad. Sci. U.S.A. 83, 4576-4579. doi: 10.1073/pnas.83.12.4576

Jorgenson, J. W., Novotny, M. V., Carmack, M., Copland, G. B., Wilson, S. R., Katona, S., et al. (1978). Chemical scent constituents in the urine of the red fox (Vulpes vulpes L.) during the winter season. Science 199, 796-798. doi: $10.1126 /$ science.199.4330.796

Kaissling, K. E. (2014). "Pheromone reception in insects: the example of silk moths," in Neurobiology of Chemical Communication, Chapter 4, ed C. Mucignat-Caretta (Boca Raton,FL: CRC Press), 99-146.

Kavaliers, M., and Colwell, D. D. (1995). Decreased predator avoidance in parasitized mice: neuromodulatory correlates. Parasitology 111, 257-263. doi: $10.1017 /$ S0031182000081816

Kendrick, K. M. (2014). Pheromones: the scent of a male. Curr. Biol. 24, R228-R230. doi: 10.1016/j.cub.2014.02.019

Kovacs, E. K., Crowther, M. S., Webb, J. K., and Dickman, C. R. (2012). Population and behavioral responses of native prey to alien predation. Oecologia 168, 947-957. doi: 10.1007/s00442-011-2168-9

Kwak, J., Grigsby, C. C., Preti, G., Rizki, M. M., Yamazaki, K., and Beauchamp, G. K. (2013a). Changes in volatile compounds of mouse urine as it ages: their interactions with water and urinary proteins. Physiol. Behav. 120, 211-219. doi: 10.1016/j.physbeh.2013.08.011
Kwak, J., Grigsby, C. C., Smith, B. R., Rizki, M. M., and Preti, G. (2013b). Changes in volatile compounds of human urine as it ages: their interaction with water. J. Chromatogr. B Anal. Technol. Biomed. Life Sci. 941, 50-53. doi: 10.1016/j.jchromb.2013.09.040

Lindgren, P. M. F., Sullivan, T. P., and Crump, D. R. (1995). "Review of synthetic predator odor semiochemicals as repellents for wildlife management in the Pacific Northwest," in National Wildlife Research Center Repellents Conference, Paper 24 (Lincoln: University of Nebraska).

Lloyd, R., Alford, R. A., and Schwarzkopf, L. (2009). Chemical discrimination among predators by lizards: responses of three skink species to the odours of high-and low-threat varanid predators. Aust. Ecol. 34, 50-54. doi: 10.1111/j.1442-9993.2008.01881.x

Lönnstedt, O. M., McCormick, M. I., Meekan, M. G., Ferrari, M. C. O., and Chivers, D. P. (2012). Learn and live: predator experience and feeding history determines prey behaviour and survival. Proc. R. Soc. B 279, 2091-2098. doi: $10.1098 / \mathrm{rspb} .2011 .2516$

Ma, W., Miao, Z., and Novotny, M. V. (1998). Role of the adrenal gland and adrenal-mediated chemosignals in suppression of estrus in the house mouse: the Lee-Boot Effect revisited. Biol. Reprod. 59, 1317-1320. doi: 10.1095/biolreprod59.6.1317

Macey, R. (2008, June 12). Dingo pee a potent possum 'piss off'. Environment.

May, M. D., Bowen, M. T., McGregor, I. S., and Timberlake, W. (2012). Rubbings deposited by cats elicit defensive behavior in rats. Physiol. Behav. 107, 711-718. doi: 10.1016/j.physbeh.2012.03.007

McGregor, I. S., Schrama, L., Ambermoon, P., and Dielenberg, R. A. (2002). Not all "predator odours" are equal: cat odor but not 2,4,5-trimethylthiazoline (TMT; fox odour) elicits specific defensive behaviours in rats. Behav. Brain Res. 129, 1-16. doi: 10.1016/S0166-4328(01)00324-2

Mella, V. S. A., Banks, P. B., and McArthur, C. (2014b). Negotiating multiple cues of predation risk in a landscape of fear: what scares free-ranging brushtail possums? J. Zool. 294, 22-30. doi: 10.1111/jzo.12146

Mella, V. S. A., Cooper, C. E., and Davies, S. J. (2014a). Behavioural responses of free-ranging western grey kangaroos (Macropus fuliginosus) to olfactory cues of historical and recently introduced predators. Aust. Ecol. 39, 115-121. doi: 10.1111/aec.12050

Miyazaki, M., Yamashita, T., Suzuki, Y., Saito, Y., Soeta, S., Taira, H., et al. (2006). A major urinary protein of the domestic cat regulates the production of felinine, a putative pheromone precursor. Chem. Biol. 13, 1071-1079. doi: 10.1016/j.chembiol.2006.08.013

Mokbel, I., Razzouk, A., Sawaya, T., and Jose, J. (2009). Experimental vapor pressures of 2-phenylethylamine, benzylamine, trimethylamine, and cis-2,6dimethylpiperidine in the range between $0.2 \mathrm{~Pa}$ and $75 \mathrm{~Pa}$. J. Chem. Eng. Data 54, 919-822. doi: 10.1021/je800603z

Morrow, B. A., Elsworth, J. D., and Roth, R. H. (2002). Fear-like biochemical and behavioral responses in rats to the predator odor, TMT, are dependent on the exposure environment. Synapse 46, 11-18. doi: 10.1002/syn.10109

Müller-Velten, H. (1966). Über den angstgeruch bei der Hausmaus (Mus musculus L.). Z. vergl. Physiol. 52, 401-429. doi: 10.1007/BF00302294

Munoz, D., Peinado, R. A., Medina, M., and Moreno, J. (2007). Biological aging of sherry wines under periodic and controlled microaerations with Saccharomyces cerevisiae var. capensis: effect on odorant series. Food Chem. 100, 1188-1195. doi: 10.1016/j.foodchem.2005.10.065

Murray, P. J., Burns, A. C., and Davy, J. R. (2006). Development of an animal repellent-selection, efficacy and presentation. Anim. Product. Sci. 46, 851-856. doi: 10.1071/EA06004

Nersesian, C. L., Banks, P. B., and McArthur, C. (2012). Behavioural responses to indirect and direct predator cues by a mammalian herbivore, the common brushtail possum. Behav. Ecol. Sociobiol. 66, 47-55. doi: 10.1007/s00265-0111250-y

Nolte, D. L., Mason, J. R., Epple, G., Aranov, E., and Campbell, D. L. (1994). Why are predator odors aversive to prey? J. Chem. Ecol. 20, 1505-1516. doi: 10.1007/BF02059876

Novotny, M. V., Harvey, S., and Jemiolo, B. (1990). Chemistry of male dominance in the house mouse, Mus domesticus. Experientia 46, 109-113. doi: 10.1007/BF01955433

Novotny, M. V., Jemiolo, B., Harvey, S., Wiesler, D., and Marchlewska-Koj, A. (1986). Adrenal-mediated endogenous metabolites inhibit puberty in female mice. Science 231, 722-725. doi: 10.1126/science. 3945805 
Onishi, M., Guymon, J. F., and Crowell, E. A. (1977). Changes in some volatile constituents of brandy during aging. Am. J. Enol. Vitic. 28, 152-158.

Osada, K., Kurihara, K., Izumi, H., and Kashiwayanagi, M. (2013). Pyrazine analogues are active components of wolf urine that induce avoidance and freezing behaviours in mice. PLOS ONE 8:e61753. doi: 10.1371/journal.pone.0061753

Parsons, M. H., and Blumstein, D. T., (2010a). Familiarity breeds contempt: kangaroos persistently avoid areas with experimentally deployed dingo scents. PLOS ONE 5:e10403. doi: 10.1371/journal.pone.0010403

Parsons, M. H., and Blumstein, D. T. (2010b). Feeling vulnerable? Indirect risk cues differently influence how two marsupials respond to novel dingo urine. Ethology 116, 972-980. doi: 10.1111/j.1439-0310.2010.01810.x

Parsons, M. H., Blumstein, D. T., and Dods, K. C. (2012). An in situ vertebrate bioassay helps identify potential matrices for a predator-based synthetic management tool. Wildl. Soc. Bull. 36, 383-388. doi: 10.1002/wsb.144

Parsons, M. H., Lamont, B. B., Kovacs, B. R., and Davies, S. J. (2007). Effects of novel and historic predator urines on semi-wild Western Grey Kangaroos. J. Wildl. Manag. 71, 1225-1228. doi: 10.2193/2006-096

Powell, F., and Banks, P. B. (2004). Do house mice modify their foraging behaviour in response to predator odours and habitat? Anim. Behav. 67, 753-759. doi: 10.1016/j.anbehav.2003.08.016

Preti, G., Muetterties, E. L., Furman, J. M., Kennelly, J. J., and Johns, B. E. (1976). Volatile constituents of dog (Canis familiaris) and coyote (Canis latrans) anal sacs. J. Chem. Ecol. 2, 177-186. doi: 10.1007/BF00987740

Ramp, D., Russell, B. G., and Croft, D. B. (2005). Predator scent induces differing responses in two sympatric macropodids. Aust. J. Zool. 53, 73-78. doi: 10.1071/ZO04053

Raymer, J., Wiesler, D., Novotny, M., Asa, C., Seal, U. S., and Mech, L. D. (1984). Volatile constituents of wolf (Canis lupus) urine as related to gender and season. Experientia 40, 707-709. doi: 10.1007/BF01949734

Raymer, J., Wiesler, D., Novotny, M., Asa, C., Seal, U. S., and Mech, L. D. (1986). Chemical scent constituents in urine of wolf (Canis lupus) and their dependence on reproductive hormones. J. Chem. Ecol. 12, 297-314. doi: 10.1007/BF01045612

Russell, B. G., and Banks, P. B. (2005). Responses of four Critical Weight Range (CWR) marsupials to the odours of native and introduced predators. Aust. Zool. 33, 217-222. doi: 10.7882/AZ.2005.018

Russell, B. G., and Banks, P. B. (2007). Do Australian small mammals respond to native and introduced predator odors? Aust. Ecol. 32, 277-286. doi: 10.1111/j.1442-9993.2007.01685.x

Schildknecht, H., and Birkner, C. (1983). Struktur und Wirkung der MustelidenÖkomene III. Analyse der Analbeutelsekrete Mitteleuropäischer Musteliden. Chemiker-Ztg 107, 267-270.

Schildknecht, H., Birkner, C., and Krau,B, D. (1981). Struktur und Wirkung der Musteliden-Ökomene II. Erweiterte Analyse des Analbeutelsekrets des Nerzes. Mustela Vison L. Chemiker-Ztg 105, 273-286.

Schildknecht, H., and Hiller, H. (1984). Struktur und wirkung der mustelidenökomene IV. Analyse verhaltensaktiver Drüsensekrete des Dachses (Meles meles L.). Chemiker-Ztg. 108, 1-5.

Schildknecht, H., Wilz, I., Enzmann, F., Grund, N., and Ziegler, M. (1976). Mustelan, the malodorous substance from the anal gland of the mink (Mustela vison) and the polecat (Mustela putorius). Angw. Chem. Int. Ed. Engl. 4, 242-243. doi: 10.1002/anie.197602421

Schneider, D., Kasang, G., and Kaissling, K. E. (1968). Determination of the olfactory threshold of Bombyx mori with tritium-labelled bombycol. Naturwissenschaften 55, 395. doi: 10.1007/BF00593307

Spencer, E. E., Crowther, M. S., and Dickman, C. R. (2014). Risky business: do native rodents use habitat and odor cues to manage predation risk in Australian deserts? PLoS ONE 9:e90566. doi: 10.1371/journal.pone.0090566
Staples, L. G., and McGregor, I. S. (2006). Defensive responses of Wistar and Sprague-Dawley rats to cat odour and TMT. Behav. Brain Res. 172, 351-354. doi: 10.1016/j.bbr.2006.04.011

Sullivan, T. P., Crump, D. R., and Sullivan, D. S. (1988a). Use of predator odors as repellents to reduce feeding damage by herbivores: III. Northern Montane and meadow voles (Microtus montanus and Microtus pennsylvanicus). J. Chem. Ecol. 14, 363-377. doi: 10.1007/BF01022552

Sullivan, T. P., Crump, D. R., and Sullivan, D. S. (1988b). Use of predator odors as repellents to reduce feeding damage by herbivores: IV. Montane and meadow voles (Microtus montanus and Microtus pennsylvanicus). J. Chem. Ecol. 14, 379-389. doi: 10.1007/BF01022553

Takahashi, L. K. (2014). Olfactory systems and neural circuits that modulate predator odor fear. Front. Behav. Neurosci 8:72. doi: 10.3389/fnbeh.2014.00072

Trinh, K., and Storm, D. R. (2003). Vomeronasal organ detects odorants in absence of signaling through main olfactory epithelium. Nat. Neurosci. 6, 519-525. doi: $10.1038 / \mathrm{nn} 1039$

Vernet-Maury, E. (1980). Trimethylthiazoline in fox feces: a natural alarming substance for the rat. Olfaction Taste 7, 407.

Vet, L. E. M. (1999). From chemical to population ecology: infochemical use in an evolutionary context. J. Chem. Ecol. 25, 31-49. doi: 10.1023/A:1020833015559

Voznessenskaya, V. V. (2014). "Influence of cat odor on reproductive behavior and physiology in the house mouse (Mus musculus)", in Neurobiology of Chemical Communication, ed C. Mucignat-Caretta (Boca Raton, FL: CRC Press), 389-406.

Wallace, K. J., and Rosen, J. B. (2000). Predator odor as an unconditioned fear stimulus in rats: elicitation of freezing by trimethylthiazoline, a component of fox feces. Behav. Neurosci. 114, 912-922. doi: 10.1037/0735-7044.114.5.912

Whitten, W. K., Wilson, M. C., Jorgenson, J. W., Novotny, M. V., and Carmack, M. (1980). Induction of marking behavior in wild red foxes (Vulpes vulpes L.) by synthetic urinary constituents. J. Chem. Ecol. 6, 49-55. doi: 10.1007/BF00987526

Wilson, M. C., Whitten, W. K., Wilson, S. R., Jorgenson, J. W., Novotny, M., and Carmack, M. (1980). "Marking behavior in wild red foxes in response to synthetic volatile urinary compounds," in Chemical Signals: Vertebrates and Aquatic Invertebrates, eds D. Müller-Schwartze and R. M. Silverstein (New York, NY: Plenum Press), 29-38. doi: 10.1007/978-1-4684-1027-3_3

Woolfson, A., and Rothschild, M. (1990). Speculating about pyrazines. Proc. R. Soc. Lond. B 242, 113-119. doi: 10.1098/rspb.1990.0113

Woolhouse, A. D., and Morgan, D. R. (1995). An evaluation of repellents to suppress browsing by possums. J. Chem. Ecol. 21, 1571-1583. doi: $10.1007 / B F 02035153$

Zhang, J. X., Soini, H. A., Bruce, K. E., Wiesler, D., Woodley, S. K., Baum, M. J., et al. (2005). Putative chemosignals of the ferret (Mustela furo) associated with individual and gender recognition. Chem. Senses 30, 727-737. doi: 10.1093/chemse/bji065

Zöttl, M., Lienert, R., Clutton-Brock, T., Millesi, E., and Manser, M. B. (2013). The effects of recruitment to direct predator cues on predator responses in meerkats. Behav. Ecol. 24, 198-204. doi: 10.1093/beheco/ars154

Conflict of Interest Statement: The authors declare that the research was conducted in the absence of any commercial or financial relationships that could be construed as a potential conflict of interest.

Copyright (c) 2015 Apfelbach, Parsons, Soini and Novotny. This is an open-access article distributed under the terms of the Creative Commons Attribution License (CC $B Y)$. The use, distribution or reproduction in other forums is permitted, provided the original author(s) or licensor are credited and that the original publication in this journal is cited, in accordance with accepted academic practice. No use, distribution or reproduction is permitted which does not comply with these terms. 